\title{
The hereditary mechanism and the search for the unknown factors of evolution $^{\dagger}$
}

\author{
Henry Fairfield Osborn
}

\begin{abstract}
"Disprove Lamarck's principle and we must assume that there is some third factor in Evolution of which we are now ignorant."

Chief among the unknown factors of evolution are the relations which subsist between the various stages of development and the environment.
\end{abstract}

A study of the recent discussion in the Contemporary Review between Spencer and Weismann leads to the conclusion that neither of these acknowledged leaders of biological thought supports his position upon inductive evidence. Each displays his main force in destructive criticism of his opponent; neither presents his case constructively in such a manner as to carry conviction either to his opponent or to others. In short, beneath the surface of fine controversial style we discern these leaders respectively maintaining as finally established, theories which are less grounded upon fact than upon the logical improbabilities of rival theories. Such a conclusion is deeply significant; to my mind it marks a turning point in the history of speculation, for certainly we shall not arrest research with any evolution factor grounded upon logic rather than upon inductive demonstration. A retrograde chapter in the history of science would open if we should do so and should accept as established, laws which rest so largely upon negative reasoning.

The growing sentiment of the necessity of induction and of inductive evidence is the least conspicuous, but really the most important and lasting outcome of this prolonged discussion. Weismann is the real initiator of this outcoming movement although it has taken a radical direction he neither foresaw nor advocated, for his position is eminently conservative. In fact his first permanent service to Biology is his demand for direct evidence of the Lamarckian principle, which has led to the counter- demand for such evidence of his own Selection principle, which by his own showing, and still more by his own admission in this discussion with Spencer, he is unable to meet. His second permanent service, as Professor E. B. Wilson reminds the writer, is that he has brought into the foreground the relation between the hereditary mechanism and evolution.

What have we gained in the controversy of the past decade unless it is closer thinking and this keener appreciation of the necessity for more observation? We carry forth, perhaps, some new and useful working hypotheses as to possible modes of evolution, and a fuller realization of the immense difficulties of the heredity problem-but these are only indirect gains. It is a direct gain that these negative results have led a minority of biologists into a total reaction from speculation and into a generally agnostic temper towards modern theories which is far more healthy and hopeful than the confident spirit of the majority upon either the Neo-Lamarckianor the Neo-Darwinian side. There is no note of progress in the dogmatic assertion that the question is established either as Spencer or as Weismann would have it, unless this assertion can be backed up by proof, and by whom can proof be presented if not by these masters of the subject? The conviction we all reach when we sift wheat from chaff, and bring together from all sources phenomena of different kinds and seek to discern what the exact bearings of these phenomena are, is that we are still on the threshold of the evolution problem, and that the secret is largely tied up with

\footnotetext{
†Opening a discussion before the Sections of Geology and Botany at Detroit. Published in “The American Naturalist," vol. XXXI, November 1897, p. 944-951, CrossRef.

${ }^{1}$ Osborn: Are Acquired Variations Inherited? Address before the American Society of Naturalists. Amer. Naturalist, February, 1891.
} 
that of vital phenomena in general.

The very wide and positive differences of opinion which prevail are attributable largely to the unnatural divorce of the different branches of biology, to our extreme modern specialization, to our lack of eclecticism in biology. We begin to grasp the magnitude of the problem only when side by side with field and laboratory data are placed palæontological data, as well as anthropological, including the unique facts of human variation and the laws of human inheritance. For in modern embryology certainly the most brilliant discovery is that the physical basis of all inheritance is the same-and growing out of this is the high probability that the laws of heredity are the same in the whole organic world,with no barriers between protozoa and metazoa, or between animals and plants. Both Weismann and Spencer show themselves blind to this nexus of fundamental uniformity when they draw certain lines of division in inheritance where none exist in the visible hereditary mechanism of chromatin and archoplasm. With these discoveries in mind does not Weismann appear as much afield when he maintains that the inheritance of acquired characters is a declining principle in the ascent of life, as Spencer when he maintains that it is a rising principle in the ascent of life?

The first step then towards progress is the straightforward confession of the limits of our knowledge and of our present failure to base either Lamarckism or Neo-Darwinism as universal principles upon induction. The second is the recognition that all our thinking still centers around the five working hypotheses which have thus far been proposed; namely, those of Buffon, Lamarck, St. Hilaire, Darwin, and Nägeli. Modern criticism has highly differentiated, but not essentially altered these hypothetical factors since they were originally conceived. Darwin's 'survival of the fittest' we may alone regard as absolutely demonstrated as a real factor, without committing ourselves as to the 'origin of fitness.' The third step is to recognize that there may be an unknown factor or factors which will cause quite as great surprise as Darwin's. The feeling that there is such first came to the writer in 1890 in considering the want of an explanation for the definite and apparently purposeful character of certain variations. ${ }^{2}$ Since then a similar feeling has been voiced by Romanes and others, and quite lately by Scott; ${ }^{3}$ but the most extreme expression of it has recently come from Driesch ${ }^{4}$ in his implication that there is a factor not only unknown but unknowable!

Theoretically neither of these five hypotheses of the day excludes the others. They may all cooperate. The role which each plays, or the fate of each in the history of speculation largely or wholly depends upon the solution of the problem of the transmission or non-transmission of acquired variations and after all that has been written on this question this must be regarded by every impartial observer as still an open one.

We are far from finally testing or dismissing these old factors, but the reaction from speculation upon them is in itself a silent admission that we must reach out for some unknown quantity. It such does exist there is little hope that we shall discover it except by the most laborious research; and while we may predict that conclusive evidence of its existence will be found in morphology, it is safe to add that the fortunate discoverer will be a physiologist.

\section{The Analysis of Variation.}

After this introductory survey let us consider as another outcome of the controversy that Variation and the related branch of research, Experimental Evolution, are now in the foreground as the most important and hopeful of the many channels into which the inductive tests of known or unknown factors may be turned. Let us make an honorable exception of those reactionists, such as Bateson ${ }^{5}$ and Weldon, who have instituted an exact investigation into the laws of Variation.

How shall the study of Variation be carried on? I totally differ at the outset from Bateson in the standpoint taken in the introduction of his work, that the best method of starting such an investigation is in discarding the analysis which rests upon the experience as well as the more or less speculative basis of past research. There is little clear insight to be gained by considering variations en masse, and in this lecture I shall put forth some reasons why this

\footnotetext{
${ }^{2}$ Op. cit., 1891.

${ }^{3}$ On Variations and Mutations. Am. Jour. Sc., November, 1894.

${ }^{4}$ Analytische Theorie der Organischen Entwickelung. Leipsic, 1894.

${ }^{5}$ W. Bateson: Materials for the Study of Variation. London, 1894.
} 
is the case as well as some principles which seems to be preliminary to an intelligent collection and arrangement of facts, upon the ground that a mere catalogue of facts will have no result. Variation is to be regarded as one of the two modes or expressions of Heredity, or as the exponent of old hereditary forces developing under new or unstable conditions. It stands in contrast not with Heredity, which includes it, but with Repetition as the exponent of old forces developing under old or stable conditions. Nägeli ten years ago ${ }^{6}$ laid stress upon this, as have latterly Weismann, Bateson, Hurst, ${ }^{7}$ and others. Nevertheless it is still widely misconceived. Hurst even regards Variation as the oldest phenomenon-an error in the other extreme, for they are rather coincident phenomena-representing the stability or instability of development. The broadest analysis we can make is that variations are divided by three planes-the plane of time, the plane of cause, and the plane of fitness. This raises the three problems to be solved regarding each variation; when did the variation originate? what caused it to originate? is it or is it not adaptive?

The student of heredity, in connection with these three planes of analysis, has then to consider the modes of heredity as complementary or interacting, for as soon as a 'variation' recurs in several generations it is practically a 'repetition,' and the repetition principle is a frequent source of apparent but not real variation or departure in the offspring from parental or race type. This relation becomes clear when we consider variations in man as seen in Anatomy and in Galton's studies of inheritance and as expressed in the following table:

\section{HEREDITY.}

\section{Repetition.}

$A$. Retrogressive to present and past type.

(a) Repetition of parental type

(b) Regression to present race type usually in several characters (= Variation from present parental type).

(c) Reversion to past type race, usually in few or single ch a r a cters (= Variation from present race type).

Palingenic Variation.

\section{Variation.}

A. Neutral both as regards present or future type. Including anomalies and abnormalities which are purely individual phenomena not in the path of evolution.
$B$. Progressive to future type.

(a) Ontogenic variation from parental type in one or more characters.

(b) Ontogenic variation from present race in several characters (= a new sub-type).

(c) Phylogenic or constant variation towards future race type, in one or more characters, constituting a new 'Variety' (= Repetition of parental type).

\section{Cenogenic Variation.}

The most profound gap in time is between 'palingenic variations,' springing from the past history of the individual, and 'cenogenic variations', which have to do only with present and future history. The former embraces more than reversion. This table gives us only our first impression of this plane of time so lightly regarded by Bateson, if indeed discrimination is possible among data of the kind he has collected. The distinctive import of human anatomy ${ }^{8}$ is that a comparison of the past and present habits of the race, or of the uses to which bones and muscles have been and are now being put, opens a possible analysis of variations both as regards their time of origin and as regards their fitness to past, present, or future uses; it is thus an inexhaustible mine for the philosophical study of variation_of

\footnotetext{
6"Vererbung und Veränderung sind, wenn sie nach dem wahren Wesen der Organismen bestimmt werden, nur scheinbare Gegensätze.” Theorie der Abstammungslehre, p. 541.

${ }^{7}$ Biological Theories. I, The Nature of Heredity. Natural Science, vol. I, No. 7, September, 1892. II, The Evolution of Heredity. Natural Science, vol. I, No. 8, October, 1892.

${ }^{8}$ R. Wiedersheim: Bau des Menschen als Zeugniss seiner Vergangenheit. Freiburg, 1887.

${ }^{9}$ H. F. Osborn: Present Problems in Evolution and Heredity. The Cartwright Lectures. I. The Contemporary Evolution of Man, etc. Wm. Wood \& Co., New York, 1891.
} 
which only the upper levels have been worked. ${ }^{9}$ Beside the human organism there is no other within our reach admitting such exact analysis of variation in the planes of time and fitness. When, again, we connect human anatomy as a field for the study of Variation with Galton's researches,although his emphasis has been chiefly upon the laws of Repetition, we begin to appreciate the far-reaching importance of his inductions. In contrast with those of Weismann they are based upon facts and will stand. In the first volume of these Marine Biological Laboratory lectures I went into some detail to show how Galton bears upon the modern evolution problem, so that here I may briefly recapitulate. He demonstrates two principles: First, that there must be some strong progressive variational tendency in organisms to offset the strongly retrogressive principle of Repetition wherever the neutralizing or swamping effect of natural interbreeding is in force, as it virtually is for most anatomical characters of the human race. Second, he shows what has not been pointed out in this connection before, that in natural inter-breeding ontogenic or individual variations are conspicuous but in the main temporary,while there is a strong undercurrent of phylogenic variations relatively inconspicuous and permanent. Other evidence supporting this latter principle comes out as we proceed.

What is the value of a distinction between ontogenic and phylogenic variations? It is this: it sets forth the widely neglected initial problem of the time of origin of a variation in the life history of the individual. This is the first step in experimentation upon variation, not only as it will afford crucial evidence as to the factors of Buffon, Lamarck, and of St. Hilaire, which hinge upon the inheritance of acquired variations, but in the coming days of exact research upon Variation in general. Let ontogenic variation-a term first used by Brooks, I believe, although I cannot point out where-include all deviations from type which have their cause in any stage of individual development. We are now beginning to fully recognize that the causes of certain kinds of variation actually can be traced to external influences upon certain stages of growth or ontogeny, and that it will be possible ultimately to determine these stages when this matter of time is established by experi- ment. Let phylogenic variation-a term first used by Nägeli ${ }^{10}$-include those departures from type which have become constant hereditary characters in certain phyletic series or even in a few generations. While all phylogenic variations must originate in ontogeny or in some stage of individual development, certainly a very small proportion of the innumerable ontogenic variations which we find in the examination or measurement of any adult individual ever become phylogenic, or constitute more than ripples upon the surface of a tide.

This vital distinction has not been regarded hitherto. The statistics of variation, as compiled by Darwin and lately by Wallace, Weldon, Bateson, and others, do not take into account that among phylogenic variations are others purely ontogenic springing up and disappearing during individual life, owing to causes connected solely with the disturbance of the typical action of the hereditary mechanism during ontogeny. In other words, these writers have without discrimination based upon variations, which may be largely or wholly ontogenic and temporary, the important principles of 'Fortuitous Variation' of Darwin and of 'Discontinuous Variation' of Bateson, whereas it is only the laws of phylogenic variation which are of real bearing upon the problem of evolution. Take as an illustration of this false method the wing measurements of birds given by Wallace. Why may not these be largely cases of purely ontogenic variation due to influences of life habit or to some purely temporary disturbance of the hereditary basis? Above all others, the Neo-Darwinians must reconsider their principle of 'fortuitous variation' which is an induction from data of miscellaneous ontogenic and phylogenic variations, because NeoDarwinism is essentially and exclusively a theory of the survival of favorable phylogenic variations.

One aspect of the variation problem of to-day may, therefore, be stated thus: What is the cause, nature, and extent of ontogenic variations in different stages of development, and under what circumstances do ontogenic variation become phylogenic?

This brings us to an analysis of ontogenic variations in the plane of time as provisionally expressed in the following table:

\footnotetext{
${ }^{10}$ Die Veränderung, die gewöhnlich der Vererbung gegenüber gestellt wird, steht nicht im Gegensatz zu dieser, sondern zur Constanz. In diesem Sinne heisst eine Veränderung constant, wenn das Gewonnene dauernd behalten, und vergänglich, wenn es bald wieder preisgegeben wird. Die constant oder die phylogenetische Veränderung . . . ist eigentlich nichts anderes als die Constitutionsänderung des Idioplasmas. Theorie der Abstammungslehre, p. 277.
} 
Origin OF VARIATIONS DURING LifE History.

A. Ontogenetic Variations.

(a) Gonagenic, i.e., those arising in the germcells, including the 'Blastogenic' in part of Weismann, the 'Primary Variations' of Emery.

(b) Gamogenic, i.e., those arising during maturation and fertilization, including the 'Blastogenic' in part of Weismann, 'Secondary,' or 'Weismannian variations' of Emery.

(c) Embryogenic, i.e., those occurring during early cell division, including the 'Blastogenic' and 'Somatogenic' in part of Weismann.

(d) Somatogenic, i.e., those occurring during larval and later development after the formation of the germ-cells.

\section{B. Phylogenic Variations.}

Variations from type originating in any of the above stages which become hereditary.

The above table illustrates limits which certainly should not be sharply drawn between the successive stages of ontogeny, although intermediate focal points of real distinction must exist. The four terms proposed are not in the sense of the 'blastogenic' and 'somatogenic' of Weismann, for there is no implication of his petitio principi, namely, of the separation of the hereditary substance or specific germ-plasm from the body-cells. Even before somatogenic separation has taken place we have little or no reason to believe that all the blastogenic, gonagenic, or gamogenic variations which may have arisen from various causes will become phylogenic.

If we carry our analysis into the 'plane of fitness' the first point which arises is whether variations are normal, including both cenogenic and palingenic
Theories of Causation.

Theoretically connected with pathological, nutritive chemico-physical, nervous influences, as implied by Kölliker and others, including the doubtful phenomena of Xenia and Telegony.

Theoretically connected with influences named above, also, with the combination of diverse ancestral characters, 'Amphimixis' of Weismann.

Theoretically connected with extensive anomalies due to abnormal segmentation and other causes, as observed in the mechanical embryology of Roux, Driesch, Wilson, and others.

Connected with reactions between the hereditary development forces of the individual and the environment. variations, or abnormal, including teratological and other malformations. The terms 'fortuitous' and 'indefinite' as opposed to 'determinate' and 'definite' may be used apart from any theory, although they have sprung up as distinguishing two opposed views as to the principles of variation. 'Fortuity' strictly implies variation round an average mean, while 'definite' is not the necessary equivalent of adaptive, but simply implies progressive or phylogenic variation in one direction which Waagen and Scott have termed "Mutation." Bateson's terms 'Continuous' and 'Discontinuous' are useful as distinguishing gradual from sudden ontogenic variation.

In general our five working hypotheses as to the factors of evolution are theoretically related to the time stages of Variation as seen in the following table:

$$
\text { Buffon's }\left\{\begin{array}{ll}
\multicolumn{2}{c}{\text { Ontogenic }} \\
a & \text { Gonagenic } \\
b & \text { Gamogenic } \\
c & \text { Embryogenic } \\
d & \text { Somatogenic } \\
& \text { Phylogenic }
\end{array}\right\} \text { St. Hilaire's }
$$

I again call attention to the fact that Neo-Darwinism has hitherto presupposed and practically assumed 'fortuitous phylogenic variation' as its basis, for it is solely related with the selection of those ontogenic variations which are also phylogenic. NeoLamarckism, on the other hand, is solely connected 
with inheritable 'somatogenic' variation. Buffon's factor of the 'direct action of the environment' plays upon all four ontogenic stages, and both theoretically and as observed by experiment, produces profound ontogenic variations; the question is, under what circumstances do such ontogenic variation in each of the four stages become phylogenic? This factor would be partly but not wholly set aside by proof that somatogenic variations are not inherited. St. Hilaire's factor of the action of environment upon early stages of development would result in purely fortuitous variations, and, as he himself clearly perceived, would require Selection to give it an adaptive direction. Nägeli's factor, on the other-hand, assumes definite but not necessarily adaptive 'phylogenic' variation-his views have been very generally misconceived on these points-and, as he pointed out, his factor would also require Selection to determine which of the definite lines of growth were adaptive.

It seems necessary to thus clearly state the relations of the time stages of variation to each of the five factors, in order to show the decisive bearings our future exact research will have upon them. For example, the proof that variation is either 'definite' or that it is 'adaptive' prior to or independently of Selection, will constitute conclusive disproof not of Darwin's theory but of Neo-Darwinism. The fate of Lamarckism, on the other hand, depends upon the demonstration that phylogenic variation is not only 'definite' and 'adaptive' but that it is anticipated by corresponding somatogenic variation.

A review of recent thought upon the variation problem shows that these life stages are becoming generally recognized. I shall pass by Lamarck's and Darwin's factors which are so thoroughly understood and speak only of the other three.

\section{BufFon's FACTOR IN VARIATION}

As regards Buffon's factor,which is the most comprehensive of all, we know that Spencer and Weismann both assumed that the direct action of the environment was primarily a factor of evolution. Weismann first regarded this solely as the protozoan source of Variation, but has recently given it a wider play in the action of environment upon the germ-cells as a cause not of definite variation but of variability. The line of research upon the dynamic action of environment in its influence upon somatogenic variation followed by Hyatt, Dall, and others, is paralleled in the more recent speculation connecting the environment directly with gonagenic and gamogenic stages, initiated by Virchow, ${ }^{11}$ Kölliker, ${ }^{12}$ Ziegler, ${ }^{13}$ Sutton, and others. In a similar vein are the suggestions of Geddes, while those of Gerlach and Ryder direct our attention mainly to mechanical alterations in the embryonic stages of development. Botanists such as Vines, Detmer, and Hoffmann have pointed to the influence of environment upon gonagenic variation. Experiments of a general character resulting principally in embryogenic and somatogenic variation have been recently carried on by Cunningham, Agassiz, and others, as illustrating the direct action of the environment. Followers of Buffon's factor are also more or less identified with Lamarckism. The distinction is mainly expressed in the terms 'kinetogenic' and 'statogenic' of Cope and Ryder; for under Buffon's factor the organism is passive, while under Lamarck's it is active. Among others who have supported Buffon's principle are Packard, Eimer, Cunningham, Ryder, and Dall.

This literature and so-called 'evidence' upon Buffon's factor exhibits the greatest confusion of interpretation, and demonstrates that our conceptions first, as regards heredity, second, as regards variation under a changed environment, require thorough recasting. ${ }^{14}$ First as regards evolution in relation to heredity. The reversion phenomena as seen in human anatomy wholly set aside Weismann's conception of evolution as the selection of favorable and the elimination of unfavorable hereditary variations; in other words, of selection acting directly upon the germplasm. These phenomena indicate rather that the direct process is not one of elimination but of suppression from the later stages of ontogeny, and that only after an enormous interval of time does actual

\footnotetext{
${ }^{11}$ R. Virchow: Descendenz and Pathologie. Virchow's Archiv, CIII, p. 1886, pp. 1-15, 205-215, 413-437. Ueber den Transformismus. Archivf. Anthropologie, 1889, p. I.

${ }^{12}$ Kölliker: Das Karyoplasma und die Vererbung. Zeitschr.f. wissenschaftl. Zoologie, 1886. Eröffnungsrede der ersten Versammlung der Anatomischen Gesellschaft in Leipzig. Anat. Anzeiger, II, 1887.

${ }^{13}$ Ernst Ziegler: Die neuesten Arbeiten über Vererbung und Abstammungslehre und ihre Bedeutung für die Pathologie. Tübingen.

${ }^{14} \mathrm{~J}$. T. Cunningham: The Problem of Variation. Natural Science, vol. III, pp. 282-287. Also, Researches on the Coloration of the Skins of Flat-Fishes. Jour. Mar. Biol. Assoc., May, 1893. (See also Trans. Roy. Soc., 1892-3).
} 
elimination occur. Abnormal nervous conditions such as seen in Anencephaly are accompanied by the revival of a large number of latent characters. In Galton's language, patent characters become latent in the course of evolution.

In Weismann's language, on the other hand, in explanation of dimorphism in hymenoptera and other types, there are certain sets of biophors corresponding to certain possibilities of adult development. Apply this to the celebrated case of the flatfishes and the remarkable results recently obtained by Agassiz, Filhol, and Giard in artificially producing more or less symmetrical flat-fishes by retaining the young near the surface. Weismann's interpretation of the evolution of flat-fishes has always been that it was by the selection of asymmetrical and elimination of symmetrical 'determinants.' In the light of these experiments he must now recast this explanation by saying that the flat-fishes have kept in reserve a set of symmetrical 'determinants' since the period when our first record of the asymmetrical type appears, or about three million years!

This attack upon the speculations of one writer is a digression. What I really wish to bring out is the necessity of a far more critical analysis of the various kinds of evidence for Buffon's factor. This necessity may be illustrated by the different interpretations of color change in direct response to changed environment.

The most significant experiments upon color are those of Cunningham upon the flat-fishes. He has proved that during the early metamorphosis of young flat-fishes, when pigment is still present on both sides, the action of reflected light does not prevent the disappearance of this pigment upon the side which is turned towards the bottom, so that the color passes rapidly through a retrograde development; but prolonged exposure to the light upon the lower side causes the pigment to reappear, and upon its reappearance the pigment spots are in all respects similar to those normally present upon the upper side of the fish. It is very important not to confuse these results, of deep interest as they are, with those obtained where the environment is new in the historic experience of the organism. Experiments upon color, therefore, afford a marked illustration of the necessity of drawing a sharp distinction between ceno- genic and palingenic variations. We have, in many cases, been mistaking repetitions of ancient types of structure for newly acquired structures. When the pale Proteus is taken from the Austrian caves, placed in the sunlight, and in the course of a month becomes darkly pigmented, there are two interpretation of this pigmentation; either that we have revived a latent character, or that we have created a new character. The latter interpretation can alone be taken as a proof of Buffon's factor when it is found to be followed by hereditary transmission.

Poulton, ${ }^{15}$ as a supporter of Neo-Darwinism, takes this view, in reply to Beddard and Bateson, and as an induction from his beautiful and exact experiments upon the coloring of lepidopterous larvæ. After producing the most widely various colorings and markings by surrounding the larvæ during ontogeny with objects of different colors, he urges that the changes thus directly produced simply revert to adaptations to former conditions of life, in other words, that they are palingenic. Whether this interpretation is correct or not, Poulton proves that, no matter how stable certain hereditary characters may appear to be, repetition in ontogeny depends upon repetition in environment, and that there are wide degrees of ontogenic variations which do not become phylogenic at least in several successive generations.

From many other analogous researches we gather the following principle to which far too little attention has been paid in the study of the phenomena of variation in their bearing upon the factors of evolution: It is that ontogenic repetition depends largely upon repetition in environment and life habit, while ontogenic variation is connected with variation in environment and life habit. If the environment be changed to an ancient one, then ontogenic variations tend to regression or reversion (i.e., palingeny) or practically to repetition of an ancient type. It is necessary to state clearly that there is practically conclusive evidence for such a principle, not only in the later stages of development, as in the respiratory metamorphoses of the Amphibia, but extending back to very much earlier stages than we have hitherto suspected. Thus a vast amount of evidence which has been brought forward as proof of Buffon's factor, i.e., of the direct action of environment in producing definite and adaptive ontogenic variations

\footnotetext{
${ }^{15}$ E. B. Poulton: Further experiments upon the color-relation between certain lepidopterous larvæ, pupæ, cocoons, and imagines and their surroundings. Trans. Ent. Soc., pt. IV, p. 293. London, 1892. (Contains a reply to Beddard and Bateson.)
} 
is in reality in many cases no proof at all.

Having thus eliminated errors of interpretation, the great question still remains as to what happens when the environment is a wholly new one in the historical experience of the organism. Do the ontogenic variations exhibit a new direction? Is this direction adaptive, i.e., towards progressive adaptation? What relations have such new conditions to the hereditary potencies of the germ cells?

Out of all actual researches it becomes clear that experimentation can henceforth be separately directed upon the four stages of development, and that it will be possible in some degree to draw such lines of separation. New mechanical and chemical influences can be applied in each stage and withdrawn in the subsequent stages, the difficulty being to reach the extreme point where a profound influence is exerted without interfering with the reproductive function.

One effect of new environment upon the gonagenic, gamogenic, and embryogenic stages will be saltation. Ryder $^{16}$ has recently treated this in a most suggestive manner in discussing the origin of Japanese gold-fish. Turning to St. Hilaire's hypothesis, we find he had in mind embryogenic saltation mainly traceable to respiratory and chemical changes. Virchow extends the cause of sudden change further back to chemico-physical influences upon the germcells. The causes and modes of sudden development arising from whatever ontogenic stage demand the most careful investigation, chiefly in their bearing upon the relation of ontogenic to phylogenic variation. Galton has discussed the subject objectively under the head of 'Stability of Sports', and Emery, under the head of 'Primary Variations,' has supported Galton's observation that such saltations often exhibit a strong capacity for inheritance. Bateson reaches in the conclusion of his work a modified form of St. Hilaire's factor of saltatory evolution, and believes that species have largely originated by 'discontinuity' of variation or the sudden accession of new characters from unknown causes, concluding that all inquiry into the causes of variation is premature. The materials he has brought together are of the greatest value, and he has already been able to throw in doubt many current beliefs, such as that variability is greater in domestic than in wild animals. His interpretation of these materials is, as we have seen, weakened, so far as it bears on our search for the evolution factors, by the fact that from the nature of most of his evidence he cannot discriminate between ontogenic and phylogenic variation; moreover, he discards any attempt to discriminate between palingenic and cenogenic variations. This lack of analysis leads him into what appears to be an entirely erroneous induction, for the principle of discontinuity is opposed by strong evidence for continuous and definite phylogenic variation as observed in actual phyletic series.

\section{Nägeli's Factor and Phylogenic Variation.}

Nägeli's factor ${ }^{17}$ introduces us to an entirely distinct territory-to the opposite extreme from saltation. It is one we can no longer set aside as transcendental because of the strong likeness it bears at first sight to the internal perfecting principle of Aristotle. It is supported in a guarded manner by Kölliker and Ziegler. It contains the large element of truth that the trend of variation and hence of evolution is predestined by the constitution of the organism; that is, granted a certain hereditary constitution and an environment favoring its development, this development will exhibit certain definite directions, which when reaching a survival value will be acted upon by selection. I have recently ${ }^{18}$ described as the 'potential of similar variation' an evolution principle which seems to be well supported by palæontological evidence. It is this: while the environment and the activity of the organism may supply the stimuli in some manner unknown to us, definite tendencies of variation spring from certain very remote ancestral causes; for example, in the middle Miocene the molar teeth of the horse and the rhinoceros began to exhibit similar variations; when these are traced back to the embryonic and also to the ancestral stages of tooth development of an early geological period, we discover that the six cusps of the Eocene crown, repeated to-day in the embryonic development of the jaw, were also the centers of phylogenic variation; these centers seem to have predetermined at what points certain new structures would appear after these two

\footnotetext{
${ }^{16}$ The inheritance of modifications due to disturbance of the early stages of development, especially in the Japanese domesticated races of gold carp. Proc. Acad. Nat. Sc. Phila., 1893, p. 75.

${ }^{17}$ C. V. Nägeli: Mechanisch-physiologische Theorie der Abstammungslehre. München und Leipzig, 1884.

${ }^{18}$ Rise of the Mammalia in North America. Contr. Biol. Dept. Columbia College, vol. I, No. 2, September, 1893.
} 
lines of ungulates had been separated by an immense interval of time. In other words, upper Miocene variation was conditioned by the structure of a lower Eocene ancestral type.

This is the proper place to recall a kindred conception of Variation which has been in the minds of many, and has been clearly formulated it appears by Waagen. It is of Variation so inconspicuous and so slight that it can only be recognized as such when we place side by sides two individuals separated by a long series of generations. ${ }^{19}$ Mark the contrast with the extreme of St. Hilaire's saltatory evolution; or again, the contrast with Darwin's and Weismann's conception of Variations, not, it is true, of a saltatory character, but as sufficiently important and conspicuous to become factors in the survival of the organism. This conception of 'phylogenic variation, as we have seen, is consistent with the application of Galton's principles to human evolution, but it finds its strongest support in palæontology, and is the unconscious motive of dissent on the part of all palæontologists, so far as I know their opinions, independently working in all parts of the world, to the fortuitous Variation and Selection theory.

Our palæontological series are unique in being phyletic series. They exhibit no evidences of fortuity in the main lines of evolution. New structures arise by infinitesimal beginnings at definite points. In their first stages they have no 'utilitarian' or 'survival' value. They increase in size in successive generations until they reach a stage of usefulness. In many cases they first rise at points which have been in maximum use, thus appearing to support the kinetogenesis theory. In extensive fossil series we also find evidence of anomalous or neutral variations, such as Bateson has brought together, but these are aside from the main lines of evolution. They present no evidence for the Neo-Darwinian principle of the accumulation of adaptive variations out of the fortuitous play around a mean of adaptive and inadaptive characters, but they present strong evidence of the Darwinian principle of the survival of the fittest. The main trend of evolution is direct and definite throughout, according to certain unknown laws and not according to fortuity. This principle of progressive adaptation may be regarded as inductively established by careful studies of the evolution of the teeth and the skeleton. Its bearing upon Lamarck's factor of the transmission of somatogenic variation was pointed out by myself in 1889; it does not positively demonstrate Lamarck's factor because it leaves open the possible working of some other factor at present unknown, and Lamarck's factor is also inadequate; but it positively sets aside Darwin's factor as universal in the origin of adaptations and as a consequence 'the allsufficiency of Natural Selection.' If Lamarck's factor is disproved, in other ways, it leaves us in vacuo so far as a working hypothesis is concerned.

The conclusions which Hyatt, Dall, Williams, Buckman, Lang, and Würtemberger have reached among invertebrates are independently paralleled by those of Cope, Ryder, Baur, Scott, ${ }^{20}$ the writer, and many other morphologists. The same general philosophical interpretation of evolution is now independently announced from an entirely different field of work by Driesch. We may waive our applications of these facts to theories, but let us not turn our backs to the facts themselves!

\section{The OUTLOOK FOR INDUCTION.}

The problems I have described are the main ones. No longer misled by palingenic variation under revival of an ancient environment, let us set ourselves rigidly to the analysis and investigation of the responses of the organism to new environment, in all four stages of development. Are these responses adaptive? Is there a teleological mechanism in living matter as Pflüger ${ }^{21}$ has expressed it? Is this mechanism in the adult reflected and accumulated in the germ?

One most hopeful outlook is in Experimental Evolution. Bacon in his Nova Atlantis three centuries ago projected an institute for such experiments, which when it finally materializes should be known as the Baconian Institute. The late Mr. Romanes proposed to establish such a station at Oxford, and went so far as to institute an important series of private experiments, which were unfortunately interrupted by his death. What we wish to ascertain is, whether

\footnotetext{
${ }^{19}$ This was brought out by the writer in his Oxford paper. See Nature, August 30, 1894, p. 435. It has recently been independently stated with great clearness by Scott in his article Variations and Mutations. American Journal of Science, November, 1894. Scott, following Waagen, revives the terms 'mutation' for what Nägeli has termed 'phylogenic variation.'

${ }^{20}$ W. B. Scott: On Some of the Factors in the Evolution of the Mammalia. Journ. of Morphology, vol. V, 1891, p. 378.

${ }^{21}$ Pflüger: Die teleologischen Mechanik der lebenden Natur. Bonn. 1877.
} 
new ontogenic variations become phylogenic, and how much time this requires.

The conditions of a crucial experiment may be stated as follows: An organism A, with an environment or habit $\mathrm{A}$, is transferred to environment or habit $\mathrm{B}$, and after one or more generations exhibits variations $B$; this organism is then retransferred to environment or habit $\mathrm{A}$, and if it still exhibits, even for single generation, or transitorily, any of the variations $B$, the experiment is a demonstration of the inheritance of ontogenic variations. These are virtually the conditions rightly demanded by NeoDarwinians for an absolute demonstration, either of Lamarck's or Buffon's principle of the inheritance of embryogenic or somatogenic variation but it is important to observe that such return to a former environment is very rare in a state of nature. There is no record that such conditions have as yet been fulfilled, for hitherto organisms have been simply retained in a new environment, and the profound modifications which are exhibited may simply be the exponents of an hereditary mechanism acting under the influence of new forces. Such experiments will probably require an extended period of time, for we learn from palæontology, as well as from palingenic variation, that phylogenic inheritance is extremely slow in a state of nature.

It is desirable to establish non-infectious experimentation involving the conditions named above, mainly as a test of Lamarck's factor. Varigny has also proposed a crucial experimental series mainly upon Buffon's factor. His volume upon Experimental Evolution is an invaluable review, especially of French researches in experimental transformism. Much of this is in the line brought together some years ago by Semper in his Animal Life. Varigny draws a valid distinction between morphological variation and physiological variation, including under the latter internal chemical and constitutional differences which are not displayed in structure but must underlie all reactions. Under the head of what I have called Gonagenic Variation, the author discusses the work of Gautier ${ }^{22}$ upon the influence of previous fertilization in plants as well as upon the chemistry of plants in connection with color variation. $\mathrm{He}$ adds to the observations of Yung and Born other studies upon sex determination. He describes the experimental teratogeny or embryonic variation of Dareste, Fallon, and later observers.

Throughout Varigny's volume it is nevertheless evident that none of the studies upon Ontogenic Variation hitherto have been specifically directed to the vital problem, as they must be in the future. Varigny makes a useful suggestion as to the importance of imitating natural conditions in experimental work, but he fails to emphasize the importance of the tests set forth above in order to ascertain whether the acquired modifications have actually been impressed upon the hereditary mechanism or merely upon the various stages of ontogeny.

\section{Conclusions.}

The general conclusion we reach from a survey of the whole field is, that for Buffon's and Lamarck's factors we have no theory of Heredity, while the original Darwin factor, or Neo-Darwinism, offers an inadequate explanation of Evolution. If acquired variations are transmitted, there must be, therefore, some unknown principle in Heredity; if they are not transmitted, there must be some unknown factor in Evolution.

As regards Selection, we find more than the theoretical objections advanced by Spencer and others. Neo-Darwinism centers upon the principles of fortuitous variation, utility, and selection as universal. In complete fossil series it is demonstrated that these three principles, however important, are not universal. Certain new adaptive structures arise gradually, according to certain definite laws, and not by fortuity.

Lamarck's and Buffon's factors afford at present only a partial explanation of these definite phylogenic variations, even if the transmission of acquired variations be granted. Nägeli's factor of certain constitutional lines of variation finds considerable verification in fossil series as a principle of determinate variation, but not as a general internal perfecting tendency. St. Hilaire's factor of occasional saltatory evolution by sudden modification of the hereditary mechanism is established, but not as yet understood, although we are perhaps approaching an explanation through experimental embryology.

Our standpoint towards Variation in relation to all the Factors requires thorough reconsideration.

\footnotetext{
${ }^{22}$ Armand Gautier: Du Mécanisme de la Variation des Etres vivants. (Hommage à Monsieur Chevreul à l'Occasion de son Centennaire). F. Alcan. Paris, 1886.
} 
The Darwinian law of Fortuity and the Buffon law of the direct action of Environment, have hitherto been inductions from variations which may be largely ontogenic and transitory. They both require confirmation on data of phylogenic variation. As for Lamarck's factor, the evidence seems to be conclusive that somatogenic variation is largely adaptive; but it remains to be proved that phylogenic variations as observed in human anatomy and in palæontology are invariably anticipated by corresponding changes in the individual, in other words, that the definite current of variation is guided by the inheritance of individual reactions and not by some other principle.

Another consideration is, that individual Variation may play a far less conspicuous role than we have assigned to it; in other words, that many of the most important changes in successive generations are so gradual as to be entirely inconspicuous in a single generation.

Our conception of the mechanism or physical basis of Heredity is also to be made much clearer by a series of experiments directed to palingenic variation, in order to ascertain how far the revival of an ancient environment arouses latent hereditary forces. The experiments already well advanced by Cunningham, Agassiz, and Poulton indicate that progressive inheritance is rather a process of substitution of certain characters and potentialities than the actual elimination implied by Weismann.

My last word is, that we are entering the threshold of the Evolution problem, instead of standing within the portals. The hardest tasks lie before us, not behind us, and their solution will carry us well into the twentieth century. 